Research Article

\title{
Structural Insight into Chitosan Supports Functionalized with Nanoparticles
}

\author{
J. Lamarra, ${ }^{1}$ L. Damonte $\mathbb{D}^{2},{ }^{2}$ S. Rivero, ${ }^{1}$ and A. Pinotti $\mathbb{D}^{1,3}$ \\ ${ }^{1}$ Centro de Investigación y Desarrollo en Criotecnología de Alimentos (CIDCA), CONICET-CIC, \\ Facultad de Ciencias Exactas, UNLP, Buenos Aires, Argentina \\ ${ }^{2}$ Departamento de Física, Facultad de Ciencias Exactas, UNLP, Buenos Aires, Argentina \\ ${ }^{3}$ Facultad de Ingeniería, UNLP, La Plata 1900, Buenos Aires, Argentina \\ Correspondence should be addressed to A. Pinotti; acaimpronta@hotmail.com
}

Received 1 September 2017; Revised 27 November 2017; Accepted 10 December 2017; Published 1 March 2018

Academic Editor: Ana María Díez-Pascual

Copyright (C) 2018 J. Lamarra et al. This is an open access article distributed under the Creative Commons Attribution License, which permits unrestricted use, distribution, and reproduction in any medium, provided the original work is properly cited.

\begin{abstract}
The incorporation of suspensions of nanoparticles functionalized with gallic acid (GA) was used as a strategy to obtain nanocomposite active films with different both chitosan : tripolyphosphate $(\mathrm{CH}: \mathrm{TPP})$ and nanoparticles: $\mathrm{chitosan}(\mathrm{N}: \mathrm{CH})$ ratios. The thermal analysis carried out by modulated differential scanning calorimetry (MDSC) allowed observing the shift of an endothermic event towards higher temperatures with a greater N:CH ratio. Analyzing ATR-FTIR spectra through principal component analysis (PCA) can be inferred that the incorporation of the nanoparticles produced a discrimination of the samples into clusters when the region $1400-1700 \mathrm{~cm}^{-1}$ was considered. The decrease in crystalline size with the inclusion of nanoparticles $\left(\mathrm{N}_{\mathrm{A}}\right.$ and $\left.\mathrm{N}_{\mathrm{B}}\right)$ proved the existence of interactions among $\mathrm{CH}$, TPP, and $\mathrm{GA}$, resulting in a more amorphous structure. The positron annihilation lifetime spectroscopy (PALS) technique was adequate to correlate the glass transition temperatures $\left(T_{g}\right)$ obtained by using the MDSC technique with parameters $\tau_{2}$ and $I_{2}$ ascribed to the annihilation of positrons in the interface. The cross section of nanocomposites obtained by scanning electron microscopy (SEM) clearly showed a homogeneous distribution of the nanoparticles without aggregation, suggesting their compatibility with the $\mathrm{CH}$ matrix. By virtue of the obtained results, the nanocomposites with the greatest nanoparticle proportion and the highest TPP concentration attained significant modifications in relation to $\mathrm{CH}$ matrices because of the crosslinking of the biopolymer with $\mathrm{GA}$ and TPP.
\end{abstract}

\section{Introduction}

Using the nanotechnology, new forms of polymeric supports with incorporation of active loaded nanoparticles can be developed to modulate their properties. The chitosan $(\mathrm{CH})$ is a cationic biopolymer obtained for deacetilation of chitin [1]. The sodium tripolyphosphate (TPP) is a multivalent anion capability of interacting with the amino groups of the $\mathrm{CH}$ and forming an ionic network interconnected by means of the ionotropic gelation technique, allowing the attainment of nanoparticles [2]. These structures facilitate the nanoencapsulation of active compounds. The gallic acid (3,4,5-trihydroxybenzoic acid) is a phenolic acid that can be found in several fruits and in processed food and beverages [3]. This active compound has recognized biological properties as an anti-inflammatory, antimutagenic, antioxidant, and antimicrobial agent [4-6]. The possibility of incorporating phenolic compounds into antimicrobial packaging proved to be of wide interest in such applications [7]. Since these components have antimicrobial activity, their release into food matrices may have a significant impact on shelf-life extension.

Considering this background, we have recently developed chitosan-based films with the incorporation of functionalized nanoparticles [2]. These nanocomposite systems demonstrated to have antimicrobial properties, and the ability to modulate the delivery of GA, hence, could be potential candidates to be used for packaging in food preservation.

According to dos Santos et al. [8], from the microstructural point of view, the incorporation of nanoparticles produces an interruption of the chitosan chains causing 
a decrease in the free volume of the system. The polymer matrix, in the vicinity of the nanoparticles, generates interphases with properties different from the bulk. Consequently, the properties of the polymer such as free volume and chain conformation experienced deviations from the bulk behavior [9].

The versatility of the positron annihilation lifetime spectroscopy technique (PALS) for the study of polymers allows an integrated approach in conjunction with complementary techniques such as ATR-FTIR, MDSC, and SEM to establish composition-structure relationships at a molecular level [10].

The incorporation of suspensions of nanoparticles functionalized with GA was used as a strategy to obtain nanocomposite active films with different both chitosan: tripolyphosphate $(\mathrm{CH}: \mathrm{TPP})$ and nanoparticles:chitosan $(\mathrm{N}: \mathrm{CH})$ ratios.

The influence of the CH:TPP $(\mathrm{v} / \mathrm{v})$ and $\mathrm{N}: \mathrm{CH}(\mathrm{v} / \mathrm{v})$ ratios on the molecular mobility and the thermal and microstructural film properties was analyzed by means of ATR-FTIR, XRD, PALS, and SEM techniques. In addition, thermal behavior of the nanocomposites was studied by using differential scanning calorimetry (MDSC), and the observed variation in the thermal transition process was discussed in relation to the PALS parameters.

\section{Materials and Methods}

2.1. Materials. Chitosan $(\mathrm{CH})$ from crab shells, with a deacetilation degree of $85 \%$ and a MW of $4.8 \times 10^{4} \mathrm{Da}$, was purchased from Polymar Ciência e Nutrição (Fortaleza, Brazil). Sodium tripolyphosphate (TPP) and acetic acid were supplied by Anedra (Buenos Aires, Argentina), and gallic acid (GA) was provided by Sigma-Aldrich Chemical Company (St. Louis, MO, USA).

2.2. Preparation of Nanoparticles. Chitosan $0.75 \%(\mathrm{w} / \mathrm{w})$ was solubilized in $0.75 \%(\mathrm{v} / \mathrm{v})$ acetic acid solution at $20^{\circ} \mathrm{C}$ under continuous agitation. Then, the corresponding amounts of GA were added to the solutions until reaching the concentration of $50 \mathrm{mg}_{\mathrm{GA}} / \mathrm{g}_{\mathrm{CH}}$ (expressed as $\mathrm{mg}$ per gram $\mathrm{CH}$ ). Sodium tripolyphosphate, used as a crosslinking agent, was prepared at the concentration of $2 \%(\mathrm{w} / \mathrm{v})$ [11]. Nanoparticles were prepared by the ionotropic gelation technique based on a modified method described by Calvo et al. [12]. TPP solution was added dropwise under continuous stirring into the solution containing $\mathrm{CH}$ and $\mathrm{GA}$ until reaching $\mathrm{CH}$ :TPP ratios of 5 and 3. Afterward, the obtained suspensions were homogenized at $13.500 \mathrm{rpm}$ for $10 \mathrm{~min}$ by using an Ultraturrax T-25 Janke \& Kunkel (IKA-Labortechnik, Germany).

2.3. Characterization of Nanoparticle Suspensions. The zeta potential (ZP) and particle hydrodynamic size of the nanoparticles were determined by a Zetasizer Nano-ZS Malvern Instruments (Worcestershire, England) equipped with a digital correlator Model ZEN3600. The morphological characteristics of the nanoparticles were analyzed by using a transmission electron microscope (JEM 1200EX II Jeol, Japan) equipped with a digital camera (ES500W Erlangshen CCD). Prior to examination, the nanoparticles were isolated by centrifugation (Beckman Coulter Optima L-100XP Floor Centrifugation System) at $20,000 \mathrm{rpm}$ for $20 \mathrm{~min}$. The supernatants were discarded, and the particles were washed several times with distilled water, redispersed, and diluted with distilled water.

2.4. Percentage Encapsulation Efficiency (PEE). To determine the percentage encapsulation efficiency, the synthesized nanoparticles were separated from the suspension by centrifugation at $20.000 \mathrm{rpm}$ for $20 \mathrm{~min}$ (Beckman Coulter Optima L-100XP Floor Centrifugation System, California, USA). Samples were filtered using $0.45 \mu \mathrm{m}$ sterile nylon (Millipore, Bedford, MA, USA), and the concentration of GA was quantified by using a Spectrophotometer DU650 (Beckman, USA). The concentration of the active agent in both the supernatant and the precipitate was calculated according to Lamarra et al. [2].

2.5. Preparation of Nanocomposite Matrices. A chitosan solution $1.5 \%(\mathrm{w} / \mathrm{w})$ was prepared by solubilization in $1.5 \%$ (v/v) acetic acid solution as described previously [2].

Different proportions of suspension of nanoparticles $\left(\mathrm{N}_{\mathrm{A}}\right.$ and $\left.\mathrm{N}_{\mathrm{B}}\right)$ were dispersed in the $\mathrm{CH}$ solutions to obtain relations $\mathrm{N}: \mathrm{CH} 1: 2,1: 1$, and $2: 1(\mathrm{v} / \mathrm{v})$. The nanocomposites were prepared by casting and drying at $37^{\circ} \mathrm{C}$ until reaching a constant weight.

From now on, the formulations with suspensions $\mathrm{N}_{\mathrm{A}}$ and $\mathrm{N}_{B}$ will be named as $\mathrm{CH}: \mathrm{N}_{\mathrm{A}}$ and $\mathrm{CH}: \mathrm{N}_{\mathrm{B}}$, indicating in each case the $\mathrm{N}: \mathrm{CH}$ ratio: $1: 2,1: 1$, and $2: 1$.

2.6. Thermal Analysis. Thermal properties of nanocomposites and $\mathrm{CH}$ films were conducted by using a DSC model Q100 controlled by a TA 5000 module (TA Instruments, New Castle, Delaware, USA), with a quench cooling accessory, under a $\mathrm{N}_{2}$ atmosphere $(20 \mathrm{ml} / \mathrm{min})$. Samples were analyzed between $-50^{\circ} \mathrm{C}$ and $200^{\circ} \mathrm{C}$ at a heating rate of $10^{\circ} \mathrm{C} / \mathrm{min}$ with a modulation period of $60 \mathrm{~s}$ and temperature amplitude of $0.5^{\circ} \mathrm{C}$. After the first scan was completed, the sample was cooled until $-50^{\circ} \mathrm{C}$ and then a second scan was recorded. All results were the average of two replicates. The total, reversing and nonreversing signals were determined. From the thermograms, the following information was obtained: $T_{p}$, the peak temperature $\left({ }^{\circ} \mathrm{C}\right) ; \Delta H$, the enthalpy ( $\mathrm{J} \cdot \mathrm{g}^{-1}$, dry basis); and $T_{g}$, the glass transition temperature $\left({ }^{\circ} \mathrm{C}\right)$, by means of Universal Analysis V1.7F software (TA Instruments, New Castle, USA).

2.7. Structural Studies. The examination of the morphology of the nanocomposites was performed with low vacuum by means of a FEI model Quanta 200 scanning electron microscope (The Netherlands).

Before the analyses, nanocomposite films were cryogenically frozen in liquid nitrogen, fractured and mounted on bronze stubs through a double sided adhesive carbon tape.

Specimens were examined at an acceleration voltage of $15 \mathrm{kV}$ without any metal or carbon coating. 
TABLE 1: Zeta potential (ZP, mV), nanoparticle diameters ( $\mathrm{nm})$, TEM micrographs, polydispersity index (PDI), and percentage encapsulation efficiency (PEE) of $\mathrm{N}_{\mathrm{A}}$ and $\mathrm{N}_{\mathrm{B}}$ suspensions. Variables were chitosan concentration (w/w), chitosan:tripolyphosphate ratio (CH:TPP), and gallic acid concentration expressed as $\mathrm{mg}_{\mathrm{GA}} / \mathrm{g}_{\mathrm{CH}}$.

\begin{tabular}{|c|c|c|c|c|c|c|c|c|}
\hline Suspension & $\mathrm{CH}(\%)$ & CH:TPP & $\mathrm{GA}(\mathrm{mg} / \mathrm{gCH})$ & $\mathrm{ZP}(\mathrm{mV})^{*}$ & Diameter $(\mathrm{nm})$ & TEM & PDI & $\mathrm{PEE}$ \\
\hline $\mathrm{N}_{\mathrm{A}}$ & 0.75 & 5 & 50 & $46.6(3.2)^{\mathrm{b}}$ & $453.1(30.0)^{\mathrm{b}}$ & & $0.61(0.02)^{\mathrm{b}}$ & $80.9(2.1)^{\mathrm{a}}$ \\
\hline $\mathrm{N}_{\mathrm{B}}$ & 0.75 & 3 & 50 & $27.7(1.2)^{\mathrm{a}}$ & $140.3(7.1)^{\mathrm{a}}$ & & $0.18(0.01)^{\mathrm{a}}$ & $80.4(1.8)^{\mathrm{a}}$ \\
\hline
\end{tabular}

${ }^{*}$ Different letters in the same column indicate significant differences $(P<0.05)$ between samples.

The structure of the nanocomposite films was also evaluated by means of X-ray diffraction in a Philips PW3710, X'Pert Pro P Analytical ModelPW3040/60 (Almelo, The Netherlands) at room temperature. The CuK radiation (1.542 $\AA$ ) was generated at $30 \mathrm{~mA}$ and $40 \mathrm{kV}$, recording the relative intensity in the scattering range of $(2 \theta) 3-60^{\circ}$ with a step size $2 \theta 0.02^{\circ}$.

The study of the contribution of each component to the interactions was carried out by means of ATR-FTIR technique. Spectra were recorded by a Nicolet, iS10 Thermo Scientific (Madison, USA), by the accumulation of 32 scans at $4 \mathrm{~cm}^{-1}$ resolution in the wavenumber range $4000-400 \mathrm{~cm}^{-1}$. Specimens were placed onto the diamond ATR crystal using a topplate and pressure-arm accessories (Smart iTX accessory) for the Nicolet $^{\mathrm{TM}}$ iS $^{\mathrm{TM}} 10$ (Thermo Scientific ${ }^{\mathrm{TM}}$, Madison, USA). Data were analyzed by using the software Omnic 8 (Thermo Scientific, Madison, USA). The spectral deconvolution of the peaks within the region $1700-1500 \mathrm{~cm}^{-1}$ (amide I and amide II bands) was performed by using curve-fitting algorithms. Inverted second derivative spectra were used to estimate the number, position, and relative contribution of individual element components of amide I and amide II. The software iterated the curve-fitting process by adjusting the high and width of the peaks to achieve the best Gaussian-shaped curves that fit the original spectrum.

2.8. Positrons Annihilation Lifetime Spectroscopy. Positron annihilation lifetime spectroscopy has been the most informative annihilation spectroscopy in characterizing the free volume of materials, especially thin films. Using a low-energy positron beam, free volume size and free volume concentration can be measured from the Ps lifetime and intensity data $[13,14]$. Usually, the third lifetime component $\left(\tau_{3}\right)$ is associated with the means radius of the free volume sites, and the intensity $I_{3}$ is related to the concentration of the free volume sites.

Samples in the form of disks of sufficient thickness $(1.3-1.5 \mathrm{~mm})$ to ensure complete stopping of the positrons were placed on either side of the Kapton foils embedding the ${ }^{22} \mathrm{Na}$ source. The lifetime spectra were recorded in a fast-fast coincidence PALS setup with a time resolution (full-width-athalf-maximum, FWHM) of 260 ps [10]. Each sample was measured three times with individual lifetime spectra having $3 \times 10^{6}$ integral counts. From the analysis, two discrete lifetimes and a continuous one corresponding to the long-lived component were obtained. This longest lifetime gives the ortho-positronium (o-Ps) lifetime component represented by the continuous distribution $1 / \tau_{3}$. Positron lifetime spectra were also analyzed using the POSITRONFIT program, giving three discrete lifetime components $\left(\tau_{1}, \tau_{2}\right.$, and $\tau_{3}$, resp.).

2.9. Statistical Analysis. For statistical analysis, Systat-software (SYSTAT, Inc., Evanston, IL, USA) version 10.0 was applied. Analysis of variance (ANOVA), linear regressions, and Fisher LSD mean comparison test were used. The significance levels used were 0.05 .

Multivariate analysis and data preprocessing were conducted on the FTIR-ATR spectra, using The Unscrambler ${ }^{\circledR}$ software (version 8, CAMO, Norway). In order to evaluate the spectral differences among samples containing different proportions of nanoparticles, a principal component analysis (PCA) was performed over ATR-FTIR spectra covering the range $1700-1400 \mathrm{~cm}^{-1}$. Taking into account the spectral differences associated with the presence of nanoparticles $\left(\mathrm{N}_{\mathrm{A}}\right.$ and $\left.\mathrm{N}_{\mathrm{B}}\right)$ in the PCA scores plot, a PLS model was calibrated to determine the relation between the TPP concentration and the absorbance corresponding to $900 \mathrm{~cm}^{-1}$.

\section{Results and Discussion}

3.1. Characterization of Nanoparticles. According to Lamarra et al. [2], chitosan is a compound which combines the electrostatic stabilization due to its positive charge and the steric stabilization because of its polymeric nature. In this way, $\mathrm{CH}$ nanoparticles were obtained as a result of molecular linkages formed by inducing the ionotropic gelation between chitosan amino group and TPP phosphates. The concentration of $\mathrm{CH}$, gallic acid $\left(\mathrm{mg}_{\mathrm{GA}} / \mathrm{g}_{\mathrm{CH}}\right)$, and $\mathrm{CH}$ :TPP ratio used to obtain the suspensions $\left(\mathrm{N}_{\mathrm{A}}\right.$ and $\left.\mathrm{N}_{\mathrm{B}}\right)$, as well as zeta potential, size values, polydispersity index (PDI), and TEM micrographs of the formed nanoparticles are shown in Table 1. As it can be seen, the lower the CH:TPP ratio, the smaller 


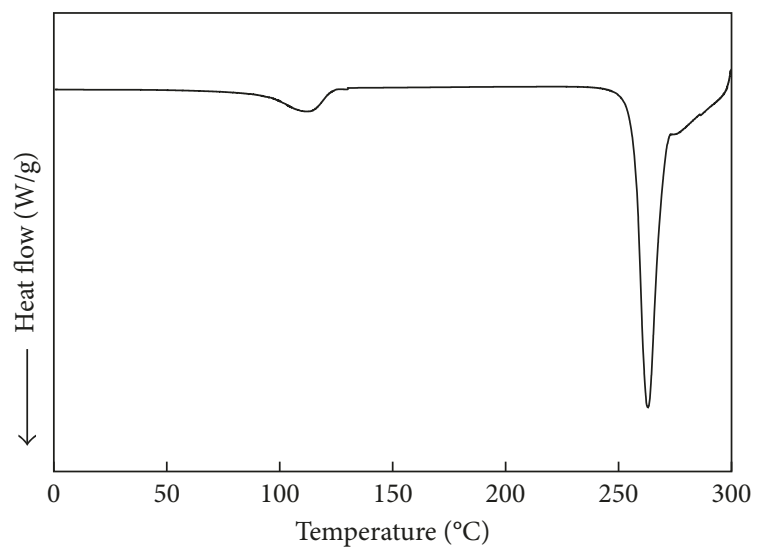

(a)

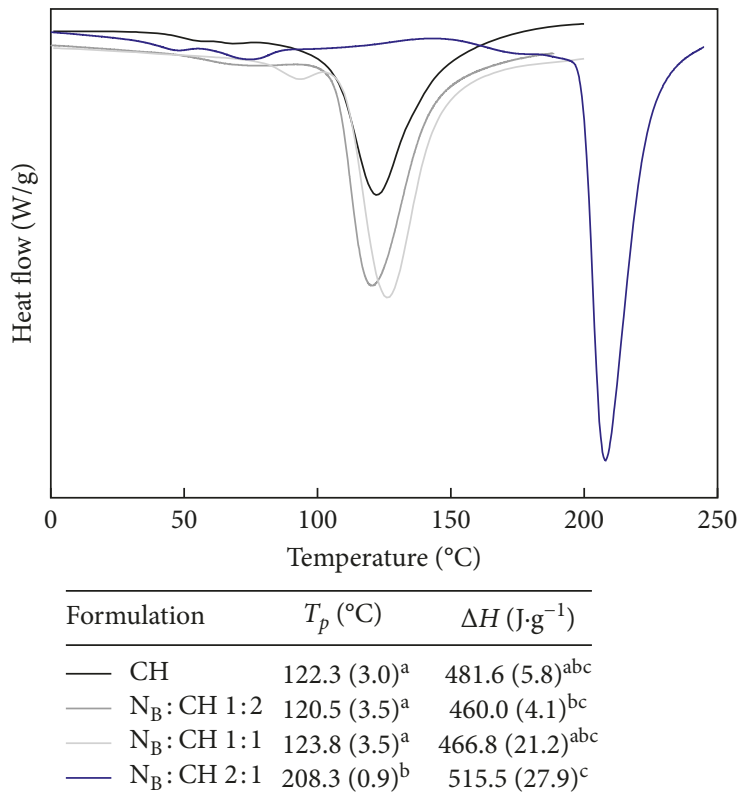

(c)

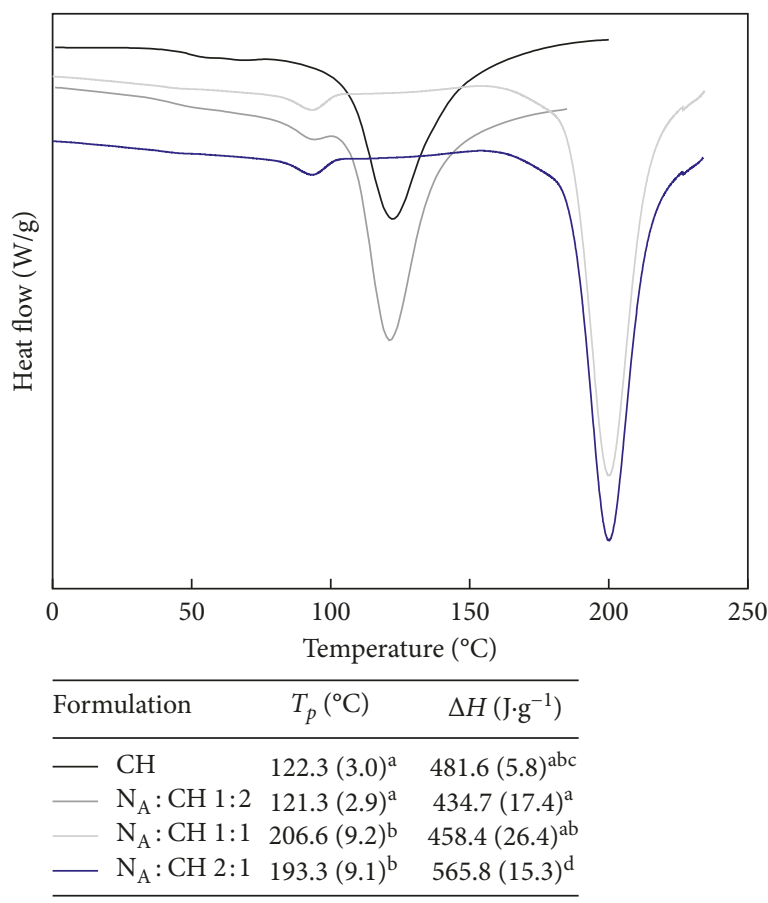

(b)

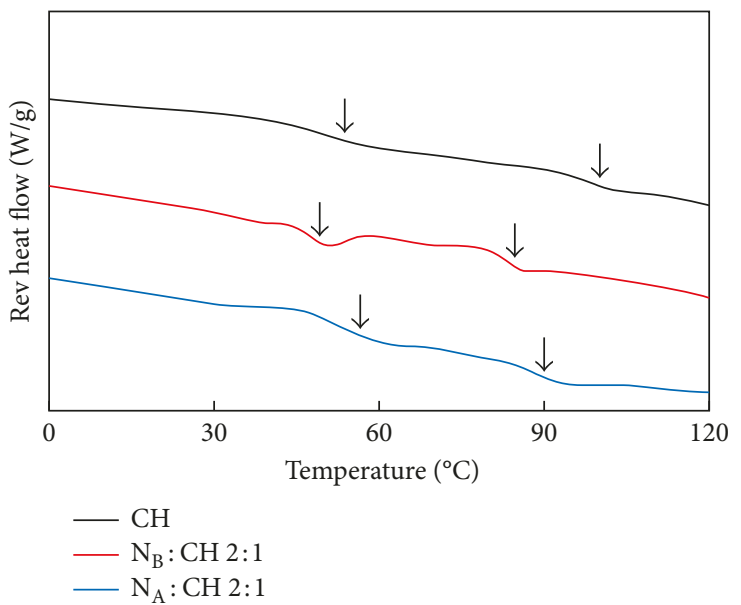

(d)

FIGURE 1: MDSC thermograms of gallic acid powder (a) and nanocomposite matrices with different $\mathrm{N}$ : $\mathrm{CH}$ ratios: $\mathrm{N}_{\mathrm{A}}(\mathrm{CH}$ : TPP 5) (b), and $\mathrm{N}_{\mathrm{B}}$ (CH : TPP 3) (c). Table shows the parameters associated with the endothermic event. Reversible heat flow curves show the glass transition temperature of $\mathrm{CH}$ (black full line), $\mathrm{N}_{\mathrm{A}}: \mathrm{CH} 2: 1$ (blue full line), and $\mathrm{N}_{\mathrm{B}}: \mathrm{CH} 2: 1$ (red full line) (d). The arrows indicate the inflection points corresponding to the $\mathrm{T}_{\mathrm{gs}}$.

the particle diameter and the lower the $\mathrm{ZP}$ obtained. The morphological analysis examined by TEM confirmed the nanosize of the formulations and indicated that the nanoparticles were roughly spherical in shape. Likewise, $\mathrm{N}_{\mathrm{B}}$ suspension exhibited a PDI value lower than 0.2 , indicating a narrow particle size distribution $(\mathrm{PDI}<0.5)$
Meanwhile, PDI of $\mathrm{N}_{\mathrm{A}}$ suspension was associated with the higher diameter obtained for these nanoparticles, giving a value higher than 0.5 .

3.2. Thermal Analysis. DSC curves for GA displayed two endothermic transitions at 112.1 and $262.8^{\circ} \mathrm{C}$ (Figure $1(\mathrm{a})$ ). 
The first transition corresponds to the water loss and the second is related to melting of the mixture of isomers of GA, considering that according to da Rosa et al. [15], the melting point of these occurs at the following temperatures: $100^{\circ} \mathrm{C}$, $221^{\circ} \mathrm{C}$, and $250^{\circ} \mathrm{C}$.

The curves obtained for the nanocomposites showed an endothermic event associated with the removal of water present in the matrix. A shift of the endothermic peak toward higher temperatures was observed as a consequence of the incorporation of higher proportion of nanoparticles (Figures 1(b) and 1(c)). The higher the $\mathrm{CH}$ : TPP ratio and, hence, the lower the crosslinking capacity, the greater the shift of the peak was. The location of the peak at the highest temperature could be attributed to the gallic acid free in the matrix whose melting is produced at $250^{\circ} \mathrm{C}[15,16]$.

Therefore, variations in the enthalpy values evidenced by DSC curves and the position of the peaks related to the water loss may reflect the molecular and physical changes caused by the interaction of the GA molecules with chitosan polymer (table in Figure 1).

According to Shavi et al. [17], the absence of an independent melting peak of the active compound in the thermogram indicates that the drug is dispersed uniformly at a molecular level in the particles. In the nanocomposite matrices coexist two phases, an enriched phase with nanoparticles loaded with GA and a phase composed of chitosan and free GA.

For formulations $\mathrm{N}_{\mathrm{A}}: \mathrm{CH} 1: 2, \mathrm{~N}_{\mathrm{B}}: \mathrm{CH} 1: 2$, and $\mathrm{N}_{\mathrm{B}}: \mathrm{CH}$ $1: 1$, the endothermic transition appear at $125^{\circ} \mathrm{C}$, approximately indicating the formation of an inclusion complex. Similar results were reported by several authors $[15,18]$.

As the $\mathrm{N}: \mathrm{CH}$ ratio increases, the amount of free GA was higher, resulting in a shift of the endothermic transition to higher temperatures, this effect being more pronounced in formulations containing $\mathrm{N}_{\mathrm{A}}$ nanoparticles. This result could be attributed to the fact that $\mathrm{N}_{B}$ contains a higher concentration of TPP that promotes ionic interactions between negative charges of crosslinker and positively charged groups.

Sharma et al. [19] informed that the glass transition of the nanocomposite matrices is used to observe the effect of the nanofillers on the thermal properties. The modifications in thermal properties as a function of the loading are also used to infer the changes in the molecular packing of polymer chains as a result of interfacial interaction between polymer and nanofillers [19].

Figure 1(d) shows the glass transition temperature $\left(T_{g}\right)$ obtained from MDSC thermograms of the reversible heat flow of the nanocomposites. The $T_{g}$ of chitosan film was observed at $91^{\circ} \mathrm{C}$ on average, which is in agreement with that informed by other authors $[20,21]$.

3.3. Film Microstructure. The micrographs of the $\mathrm{CH}$ film obtained by SEM (not shown) exposed a smooth and compact matrix, which was modified by the addition of nanoparticles. On the other hand, the cross section of nanocomposites clearly showed a homogeneous distribution of the nanoparticles without aggregation, suggesting compatibility with the $\mathrm{CH}$ matrix (Figure 2).

Micrographs of the nanocomposites exhibited a uniform dispersion of the nanoparticles forming a discontinuous phase acting as a filler immersed in a $\mathrm{CH}$ continuous network irrespective of the $\mathrm{N}: \mathrm{CH}$ ratio (Figure 2). In addition, the micrographs confirmed the minor size of the $N_{B}$ in relation to $\mathrm{N}_{\mathrm{A}}$.

According to Ghozali and Haryono [22] with the inclusion of smaller particles, it can enhance the distribution of the nanoparticles in the polymer matrix.

3.4. $D R X$. As can be seen in Figure 3, $\mathrm{CH}$ matrix exhibited peaks localized at $2 \theta=8.2,11.2,18.1$, and $23.0^{\circ}$ which are characteristics of the polymer. The inclusion of nanoparticles $\left(\mathrm{N}_{\mathrm{A}}\right.$ and $\left.\mathrm{N}_{\mathrm{B}}\right)$ induced modifications in the reflection intensities of $\mathrm{CH}$ peaks centered at $11.2^{\circ}$ and at $8.2^{\circ}$, indicating changes in the structure. It is recognized that the width of X-ray diffraction peak is related to the size of the crystallite, and the appearance of broadened peaks is the result from imperfect crystal Sujima-Anbu et al. [23]. The crystalline domains' size of $\mathrm{CH}$ and nanocomposites matrices were calculated by using the Debye-Scherrer equation [24]. The diffraction peak selected to calculate the crystalline size was the reflection near $18.1^{\circ}$ [2]. The results obtained are summarized in the table in Figure 3, which exhibits a $\mathrm{CH}$ crystalline domain size of $20.9 \mathrm{~nm}$. The decrease in crystalline size with the inclusion of nanoparticles $\left(\mathrm{N}_{\mathrm{A}}\right.$ and $\left.\mathrm{N}_{\mathrm{B}}\right)$ proved the existence of interactions among $\mathrm{CH}$, TPP, and GA, resulting in a more amorphous structure [25]. According to Sujima-Anbu et al. [23], CH nanoparticles consist of a dense network structure of interpenetrated polymer chains crosslinked to each other by TPP.

Additionally, the analysis of peak diffraction located at $2 \theta=22^{\circ}$ evidenced that the lowest $\mathrm{N}_{(\mathrm{A}, \mathrm{B})}: \mathrm{CH}$ ratio did not produce appreciable changes in the peak position. However, relations greater than $\mathrm{N}_{(\mathrm{A}, \mathrm{B})}$ : $\mathrm{CH} 1: 1$ showed a shift toward higher $2 \theta$ values (Figures 3(a) and 3(b)).

3.5. PALS Studies. For semicrystalline or amorphous materials, positrons will encounter various molecular environments such as free volume sites and crystalline defects [26]. The spectrum of a polymeric material can be fitted with three mean lifetimes, corresponding to the annihilation of p-Ps $\left(\tau_{1}, I_{1}\right)$, free positron $\left(\tau_{2}, I_{2}\right)$, and o-Ps $\left(\tau_{3}, I_{3}\right)$. Due to its sensitivity toward vacancies or defects, technique PALS has been applied to characterize $\mathrm{CH}$ nanocomposite materials.

As can be seen in Figure 4(a), the higher the $\mathrm{N}: \mathrm{CH}$ ratio, the lower the $T_{g} s$ obtained from the corresponding curves as was informed in Thermal analysis section. It is noteworthy that the molecular organization corresponded to an amorphous rubber state since the $T_{g}$ of the systems remained above the room temperature. The inclusion of the nanoparticles caused an increase in lifetime, $\tau_{3}$, and, hence, in free volume that presented a maximum for $\mathrm{N}: \mathrm{CH}$ ratio $1: 1$. 

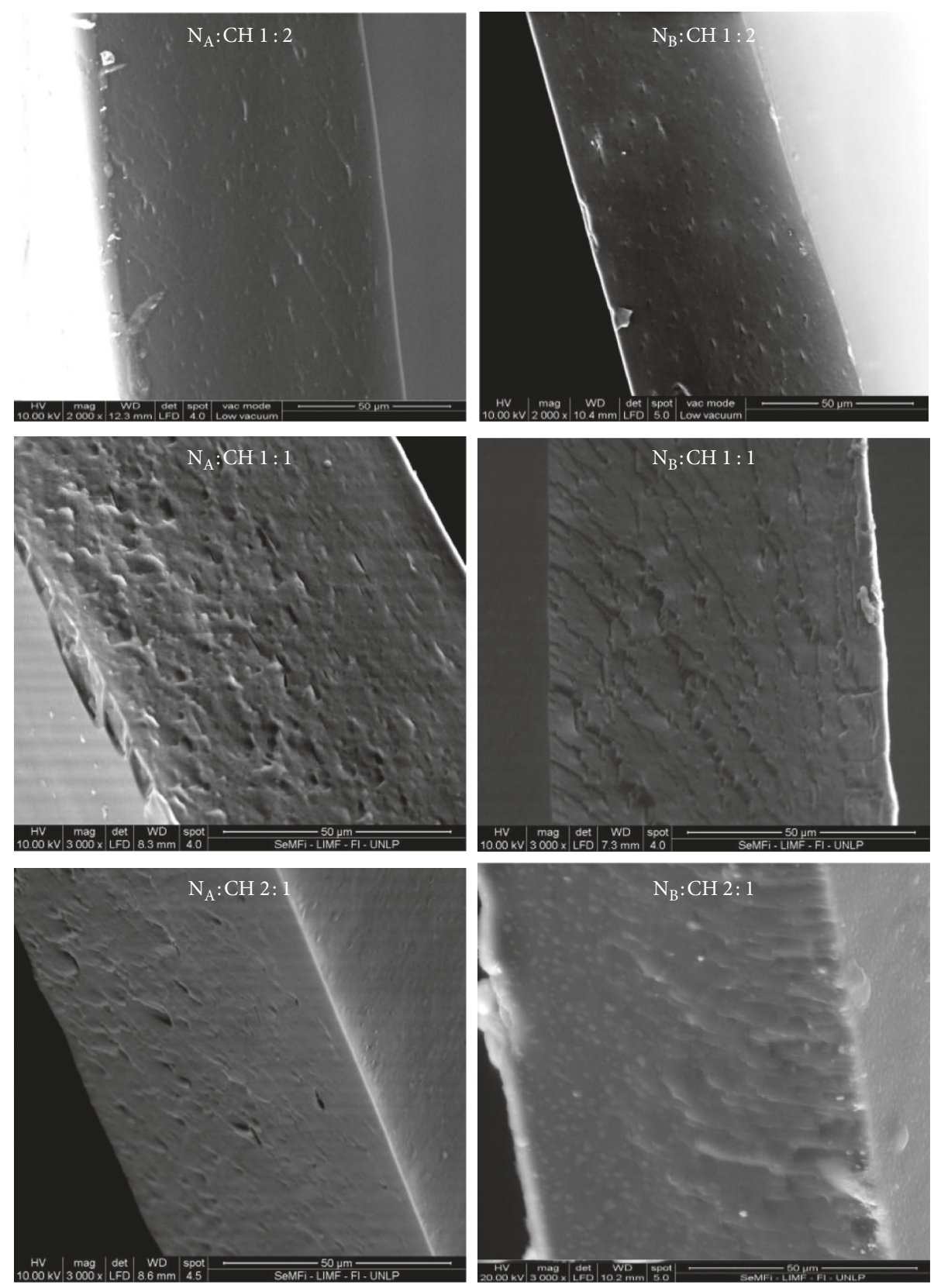

FIGURE 2: SEM cross-section micrographs of nanocomposite matrices with different $\mathrm{N}_{\mathrm{A}}: \mathrm{CH}$ and $\mathrm{N}_{\mathrm{B}}$ : $\mathrm{CH}$ ratios. Scale bars are indicated in images.

For the same nanoparticle fraction, a parallelism between $T_{g}$ values of the formulations containing either $\mathrm{N}_{\mathrm{A}}$ or $\mathrm{N}_{\mathrm{B}}$ as well as free volume values was observed. Additionally, the variables of $\mathrm{N}_{\mathrm{A}}: \mathrm{CH}$ matrices remained above those obtained for $\mathrm{N}_{\mathrm{B}}: \mathrm{CH}$ films.

It was not possible to infer the existence of a linear relation between both glass transition temperatures and the free volume irrespective of the CH:TPP ratio (data not shown). This phenomenon may, in part, depend on the fact that the analysis must be based not only on o-Ps variables but also on free positron parameters.

Consequently, considering $I_{2}$ and $\tau_{2}$, which are associated with the annihilation of positrons in interfaces, a lineal increasing relation between $T_{g} s$ and $I_{2}$ and an inverse relationship between $T_{g} s$ and $\tau_{2}$ were observed (Figures 4(a) and $4(\mathrm{~b}))$.

According to Sharma et al. [19], this lack of linearity of o-Ps lifetime could be explained considering the existence of poor dispersion (aggregation) with increasing nanoparticle concentration. The nanoparticles tend to form aggregates, which may be due to the large surface/volume ratio and intermolecular interactions, such as electrostatic, hydrophobic, and van der Waals interactions [27].

The increase in the intensity $I_{2}$ can be explained on the basis of the increase in concentration of the interfaces with the incorporation of a greater proportion of nanoparticles. 


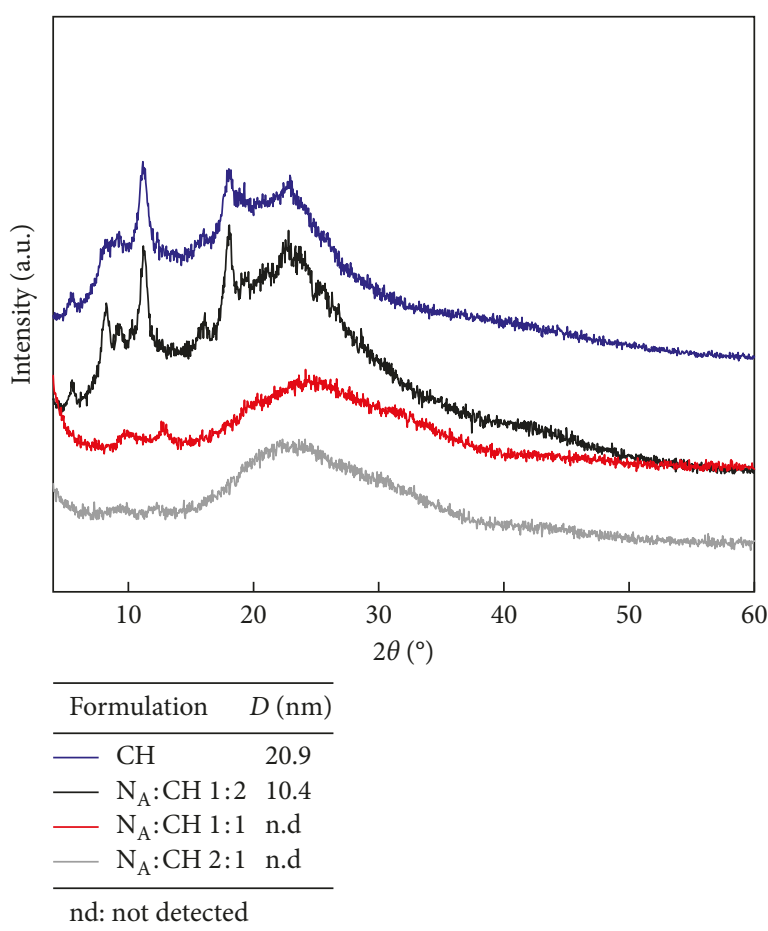

(a)

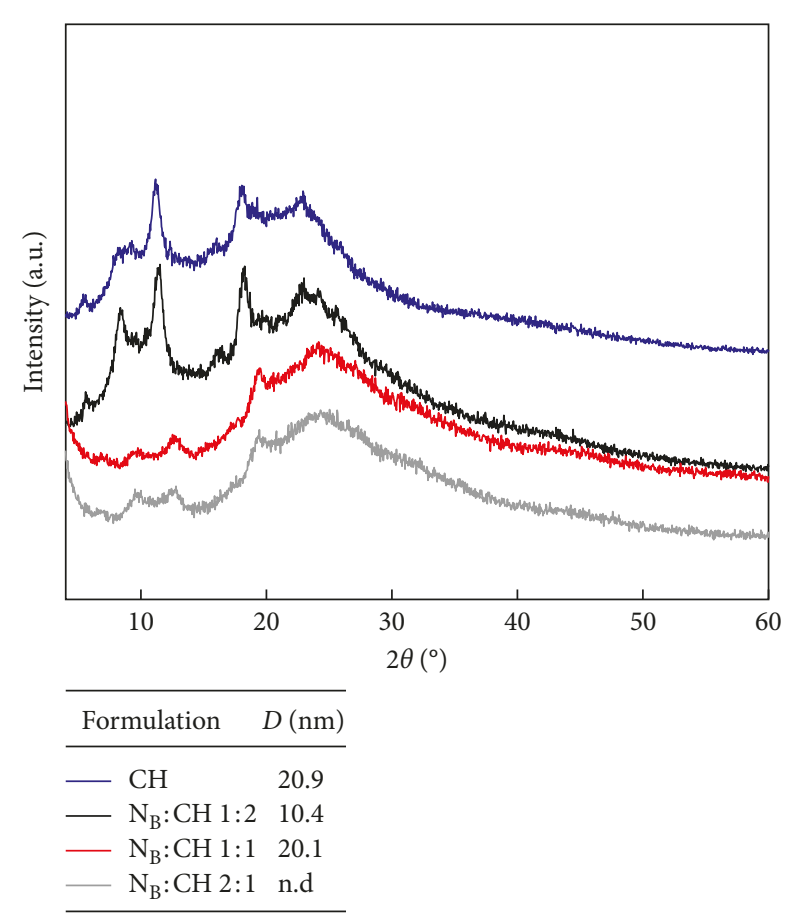

(b)

FiguRE 3: X-ray diffractograms of nanocomposites formulated with different $\mathrm{N}_{\mathrm{A}}: \mathrm{CH}$ (a) and $\mathrm{N}_{\mathrm{B}}: \mathrm{CH}$ ratios (b). Tables show the crystallite size estimated by using the Debye-Scherrer equation.

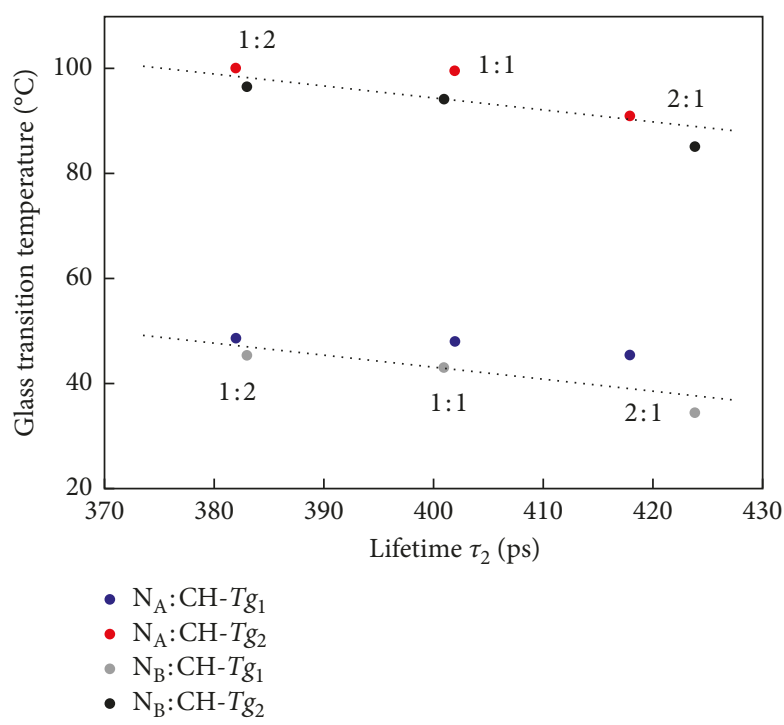

(a)

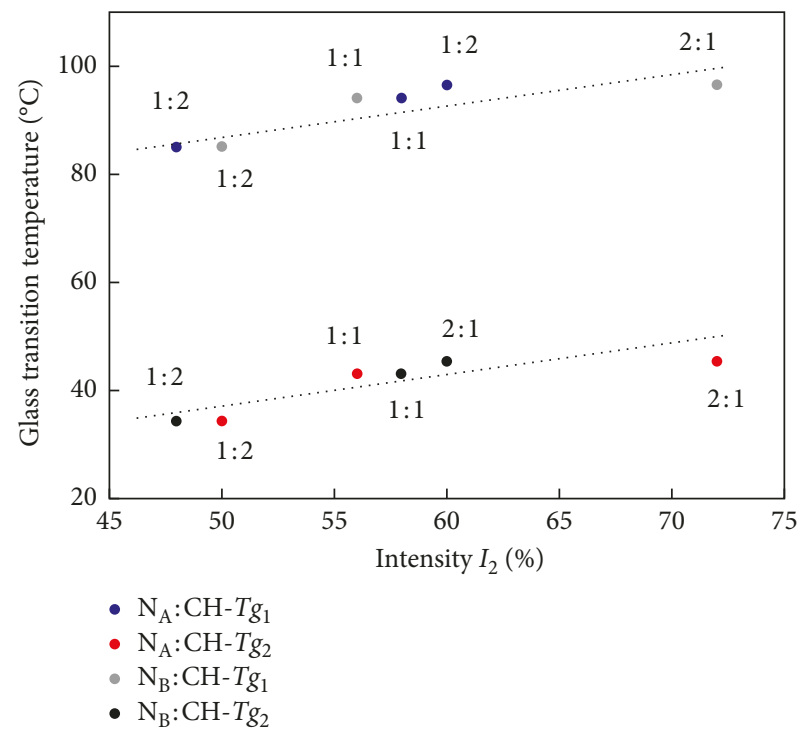

(b)

Figure 4: Correlation between (a) glass transitions temperatures $\left(T_{g 1}\right.$ and $\left.T_{g 2}\right)$ and o-Ps lifetime $\left(\tau_{2}\right)$ and (b) glass transitions temperatures $\left(T_{g 1}\right.$ and $T_{g 2}$ ) and the corresponding intensity $I_{2}(\%)$ for different $\mathrm{N}_{\mathrm{A}}: \mathrm{CH}$ and $\mathrm{N}_{\mathrm{B}}: \mathrm{CH}$ ratios.

The positron trapping process in the defects present in the interfaces proved variations in both lifetime components, $\tau_{2}$ and $\tau_{3}[28]$.

The interfacial interaction among the $\mathrm{CH}$ polymer and the nanoparticles may restrict the chain motion, leading to a reduction in size of free volume in the vicinity of the nanoparticles. As a result, o-Ps lifetime increased with the N: $\mathrm{CH}$ ratio increase.

3.6. ATR-FTIR Spectra. Nanocomposites spectra showed characteristic peaks at $1637 \mathrm{~cm}^{-1}$ (C-O stretching in amide 


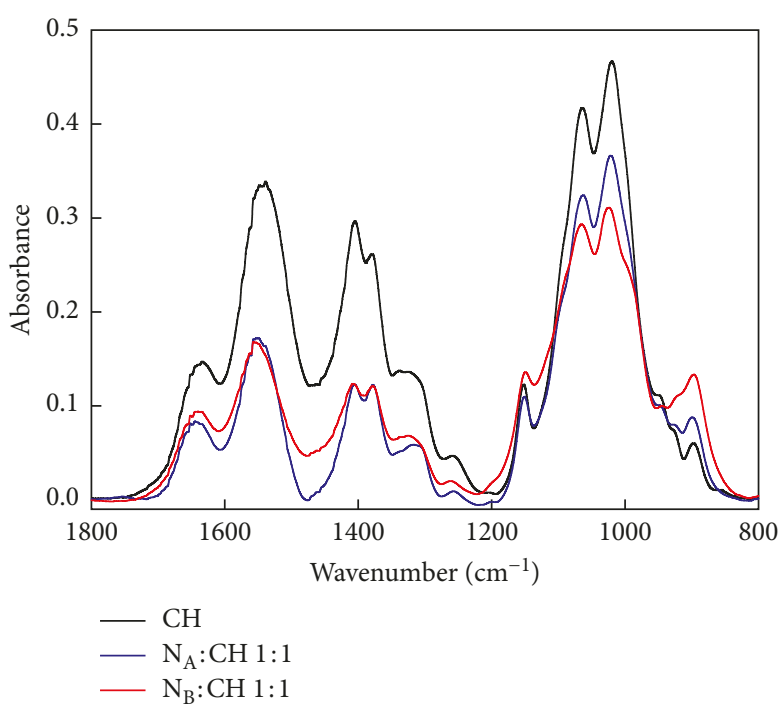

(a)

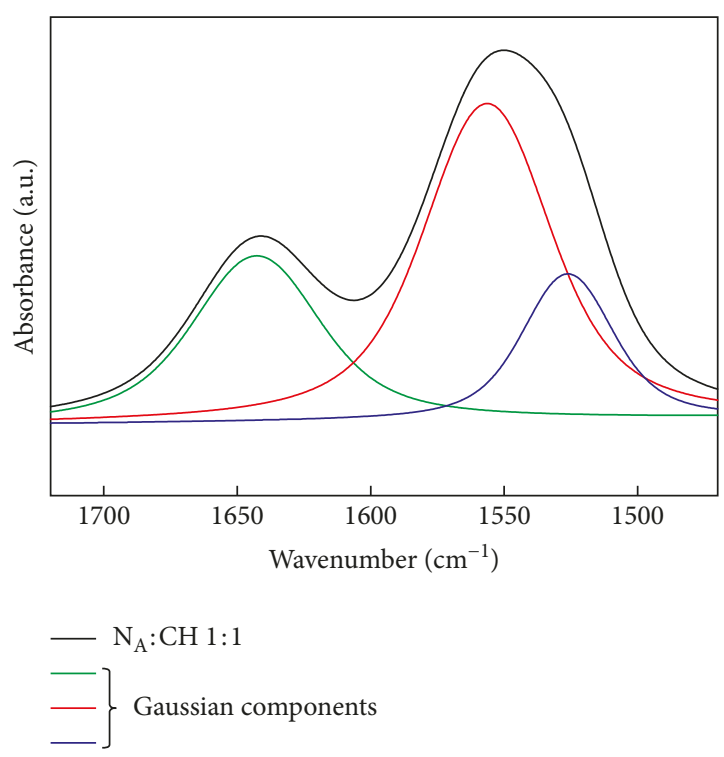

(c)

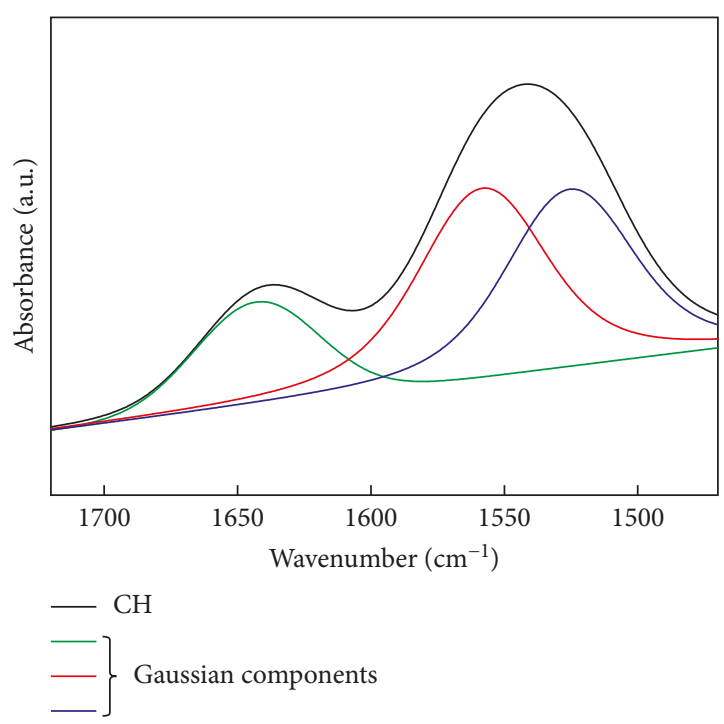

(b)

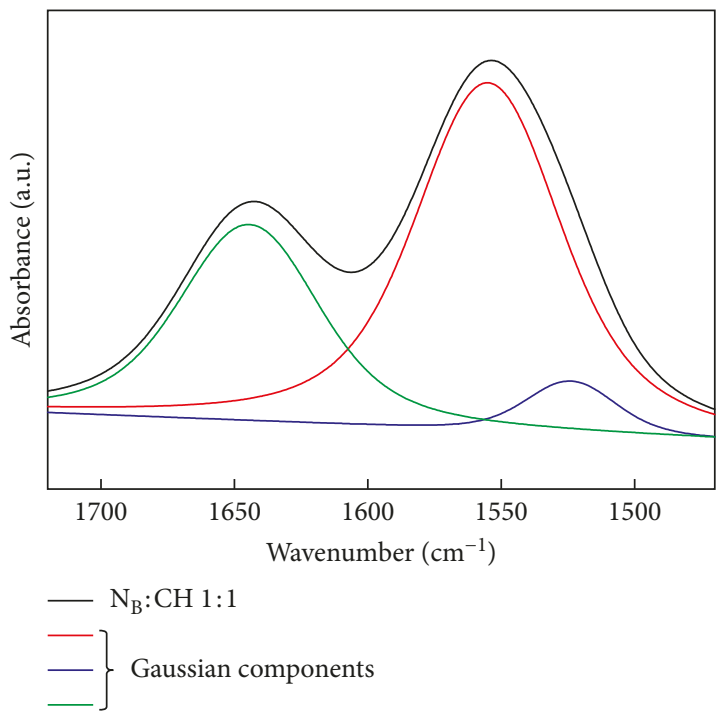

(d)

Figure 5: ATR-FTIR spectra of $\mathrm{CH}$ and nanocomposite matrices with $1: 1 \mathrm{~N}_{(\mathrm{A}, \mathrm{B})}$ : $\mathrm{CH}$ ratio showing the region $1800-800 \mathrm{~cm}^{-1}$ (a). Unresolved FTIR spectra and curve-fitting analysis in the amide I and amide II regions for $\mathrm{CH}$ (b), $\mathrm{N}_{\mathrm{A}}: \mathrm{CH} 1: 1$ (c), and $\mathrm{N}_{\mathrm{B}}$ : $\mathrm{CH} 1: 1$ (d). Experimental data (black full lines) and individual Gaussian components (color full lines) are shown.

group, amide I vibration), $1538 \mathrm{~cm}^{-1}$ (-NH $\mathrm{NH}_{2}$ bending in nonacetylated 2-aminoglucose primary amine), and $1377 \mathrm{~cm}^{-1}$ (C-O stretching of primary alcohol groups) (Figure 5). The absorption bands at $1150 \mathrm{~cm}^{-1}$ (antisymmetric stretching of the C-O-C-glycosidic linkage between chitosan monomers) and $1018 \mathrm{~cm}^{-1}$ (skeletal vibrations involving the $\mathrm{C}-\mathrm{O}$ stretching) attributed to the chitosan saccharide structure were observed [29].

Figure 5(a) depicts the development of the band at $900 \mathrm{~cm}^{-1}$ as a result of the inclusion of nanoparticles $\left(\mathrm{N}_{\mathrm{A}}\right.$ and $\left.\mathrm{N}_{\mathrm{B}}\right)$ attributed to the antisymmetric stretching of the bending P-O-P of the TPP [30]. With the increase of the nanoparticle ratio, the peak intensity significantly increased, and the shift of amide II band was visualized as a consequence of the interactions between the $\mathrm{CH}$ amino groups and the phosphate groups of the polyanion that produce an ionic crosslinking with the subsequent $\mathrm{CH}$ precipitation. These findings are analogous to those found by $\mathrm{Hu}$ et al. [31] and de Pinho Neves et al. [32].

The use of the spectra deconvolution method improved the resolution of the bands ascribed to amide I and II (Figures 5(b)-5(d)). The deconvolution of the band located at $1637 \mathrm{~cm}^{-1}$ showed a single peak after iterative curve-fitting procedure, whereas the amide II band was unfolded in two peaks located at 1555 and $1524 \mathrm{~cm}^{-1}$. Ramon et al. [33] attributed these bands to intramolecular 


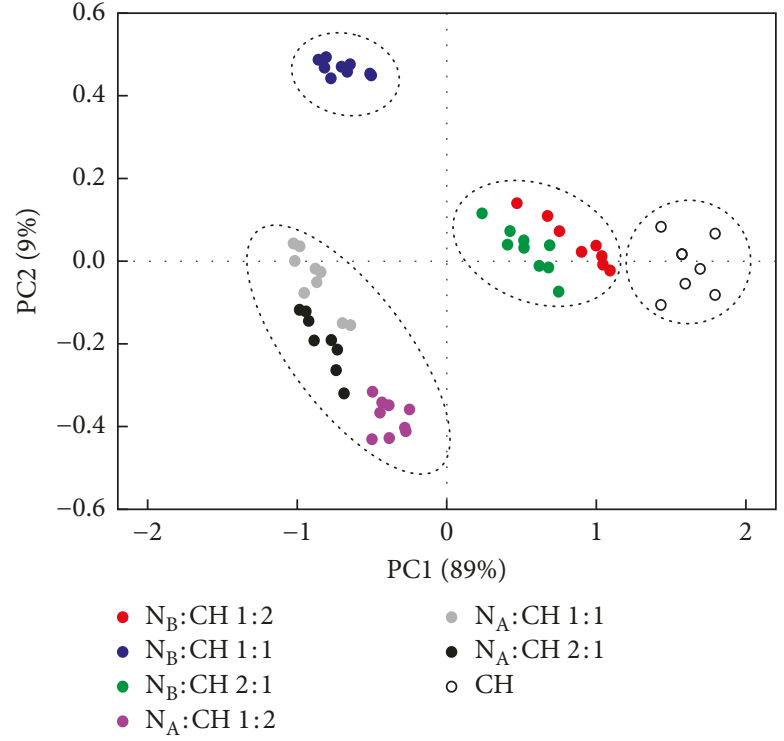

(a)

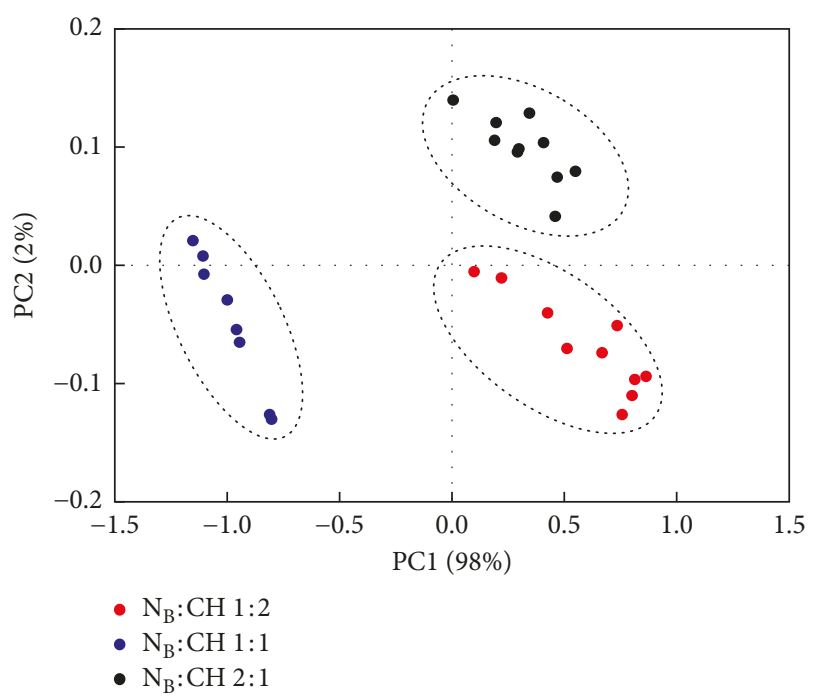

(c)

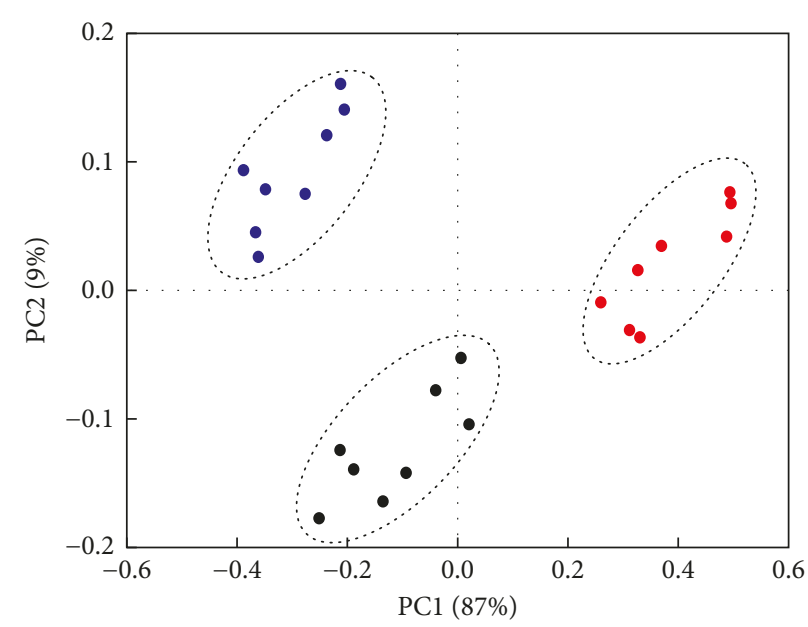

- $\mathrm{N}_{\mathrm{A}}: \mathrm{CH} 1: 2$

- $\mathrm{N}_{\mathrm{A}}: \mathrm{CH} 1: 1$

- $\mathrm{N}_{\mathrm{A}}: \mathrm{CH} 2: 1$

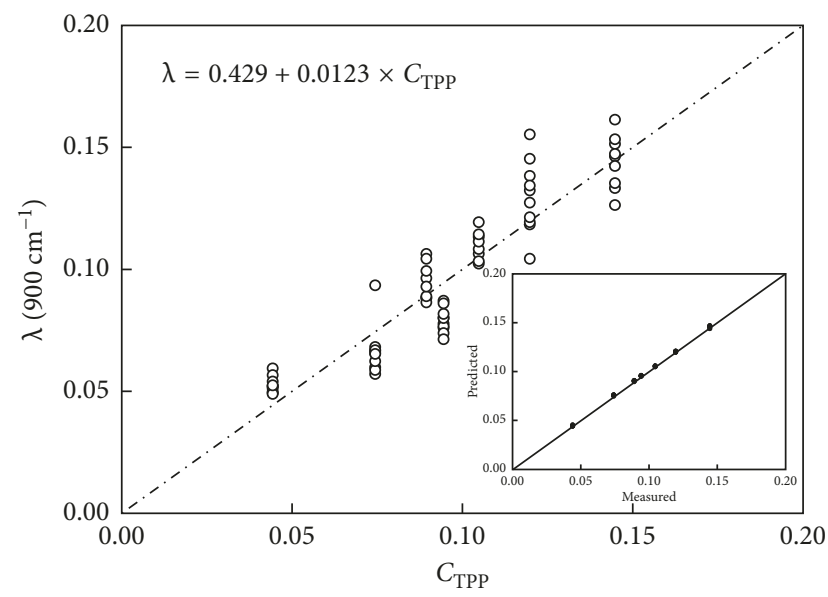

(d)

FIgURE 6: PCA biplot of $\mathrm{CH}$ and nanocomposite matrices in the ATR-FTIR region $1700-1400 \mathrm{~cm}^{-1}$ (a). PCA score plots show the cluster distribution of nanocomposites formulated with different $\mathrm{N}: \mathrm{CH}$ ratios for $\mathrm{N}_{\mathrm{A}}$ (b) and $\mathrm{N}_{\mathrm{B}}(\mathrm{c})$. Correlation between the absorbance corresponding to $900 \mathrm{~cm}^{-1}$ and the concentration of tripolyphosphate $\left(C_{\mathrm{TPP}}\right)$ obtained from PLS model (d). Figure inserted in figure (d) shows predicted versus measured values.

hydrogen-bonded, intermolecular hydrogen-bonded, and free form of non-hydrogen-bonded subbands.

3.7. PCA and PLS Analysis. Principal components analysis (PCA) was carried out to better understand the interactions of the components of the nanocomposites. The PCA analysis involves a calculation of a covariance matrix of a data set to minimize redundancy and maximize variance. In a biplot, the length of the lines approximates the variances of the variables [34]. The systematic variation of the experimental values was mainly explained by means of 2 PCs. In
Figure 6(a), the first and second principal components (PC1 and PC2) represented $89 \%$ and $9 \%$ of the total variance, respectively.

Analyzing the biplot can be inferred that the incorporation of the nanoparticles produced a discrimination of the samples $\left(\mathrm{CH}, \mathrm{N}_{\mathrm{A}}: \mathrm{CH}\right.$, and $\left.\mathrm{N}_{\mathrm{B}}: \mathrm{CH}\right)$ into clusters when the ATR-FTIR region $1400-1750 \mathrm{~cm}^{-1}$ was considered. A separation between $\mathrm{N}_{\mathrm{A}}$ : $\mathrm{CH}$ and $\mathrm{N}_{\mathrm{B}}$ : $\mathrm{CH}$ formulations along $\mathrm{PC} 1$ axis was observed, but whereas all $\mathrm{N}_{\mathrm{A}}: \mathrm{CH}$ nanocomposites were located at the left of PC2, $\mathrm{N}_{\mathrm{B}}: \mathrm{CH}$ were positioned at both sides of PC2 axis. The high percentage of variance explained in PC1 axis (89\%) indicated 
the accuracy of ATR-FTIR to discriminate among the nanocomposite matrices. In particular, the high density of the cluster corresponding to $\mathrm{N}_{\mathrm{A}}: \mathrm{CH}$ indicated the low variability among these samples (Figure 6(a)). The high overlapping of spectra corresponding to all $\mathrm{N}_{\mathrm{A}}: \mathrm{CH}$ formulations is very graphic in this respect. On the contrary, the highest variability of spectra corresponded to $\mathrm{N}_{\mathrm{B}}: \mathrm{CH} 1$ : 1 (Figure 6(a)).

Although this preliminary analysis was not able to underlined among all formulations, a posteriori analysis carried out on either $\mathrm{N}_{\mathrm{A}}$ : $\mathrm{CH}$ o $\mathrm{N}_{\mathrm{B}}$ : $\mathrm{CH}$ separately, allowed a discrimination within each of these nanocomposites in new clusters, as can be seen in Figures 6(b) and 6(c). Similar results (not shown) were obtained when the analysis was conducted on the FTIR region $2600-3600 \mathrm{~cm}^{-1}$.

Additionally, the analysis carried out by the PLS method allowed the adjustment of the experimental data of a selected wavenumber $\left(900 \mathrm{~cm}^{-1}\right)$ as a function of the TPP concentration $\left(C_{\text {TPP }}\right)$ by using the model inset in Figure $6(d)$. This peak located at $900 \mathrm{~cm}^{-1}$ was selected as a band representative of the modifications experimented by the $\mathrm{CH}$ matrix as a consequence of the incorporation of the nanoparticles. A satisfactory fit between measured and predicted values was observed (inset in Figure 6(d)).

\section{Conclusions}

The nanocomposites formulated with the highest nanoparticle proportion and the highest TPP concentration achieved significant modifications on the $\mathrm{CH}$ matrices, by virtue of the crosslinking of the biopolymer with GA and TPP, specially for $\mathrm{N}: \mathrm{CH}$ ratio $1: 1$. A further increase in the $\mathrm{N}: \mathrm{CH}$ ratio higher than $1: 1$ produced no significant improvement in the nanocomposite properties.

The results obtained by means of MDSC, ATR-FTIR, PALS, and SEM techniques showed an interaction between $\mathrm{CH}$ and GA, owing to the encapsulation of the active compound. The PALS technique was adequate to detect the modifications of both size and concentration of the free volume as a consequence of different $\mathrm{N}: \mathrm{CH}$ and $\mathrm{CH}$ :TPP ratios. In addition, this procedure showed a good correlation between glass transition temperatures $\left(T_{g}\right)$ obtained by using the MDSC technique and the PALS parameters $\tau_{2}$ and $I_{2}$ ascribed to the annihilation of positrons in the interface.

In conclusion, the structural insight revealed the changes in nanocomposites modifying the performance of the materials. In this sense, further studies are needed concerning future applications in food and agricultural fields.

\section{Conflicts of Interest}

The authors declare that they have no conflicts of interest.

\section{Acknowledgments}

This work was supported by the Argentinean Agency for the Scientific and Technological Promotion (ANPCyT) (Projects PICT 2012-0415 and 2014-1620) and the Argentinean National Research Council (CONICET) (Project PIP 2013-0109).
Authors thank Ing. Javier Lecot and Bibl.Doc. Diana Velasco for their experimental collaboration.

\section{References}

[1] A. S. Ferreira, C. Nunes, A. Castro, P. Ferreira, and M. A. Coimbra, "Influence of grape pomace extract incorporation on chitosan films properties," Carbohydrate Polymers, vol. 113, pp. 490-499, 2014.

[2] J. Lamarra, L. Giannuzzi, S. Rivero, and A. Pinotti, “Assembly of chitosan support matrix with gallic acid-functionalized nanoparticles," Materials Science and Engineering: $C$, vol. 79, pp. 848-859, 2017.

[3] A. Alberti, D. Granato, A. Nogueira, L. I. Mafra, T. A. Colman, and E. Schnitzler, "Modelling the thermal decomposition of 3, 4, 5-trihydroxybenzoic acid using ordinary least square regression," International Food Research Journal, vol. 23, pp. 30-33, 2016.

[4] S. Giftson, S. Jayanthi, and N. Nalini, "Chemopreventive efficacy of gallic acid, an antioxidant and anticarcinogenic polyphenol, against 1,2-dimethyl hydrazine induced rat colon carcinogenesis," Investigational New Drugs, vol. 28, no. 3, pp. 251-259, 2010.

[5] J. F. Rubilar, R. M. S. Cruz, R. N. Zuniga, I. Khmelinskii, and M. C. Vieira, "Mathematical modeling of gallic acid release from chitosan films with grape seed extract and carvacrol," International Journal of Biological Macromolecules, vol. 104, pp. 197-203, 2017.

[6] X. Sun, Z. Wang, H. Kadouh, and K. Zhou, "The antimicrobial, mechanical, physical and structural properties of chitosan-gallic acid films," LWT-Food Science and Technology, vol. 57, no. 1, pp. 83-89, 2014.

[7] M. R. Moreira, M. Pereda, N. E. Marcovich, and S. I. Roura, "Antimicrobial effectiveness of bioactive packaging materials from edible chitosan and casein polymers: assessment on carrot, cheese, and salami," Journal of Food Science, vol. 76, no. 1, pp. M54-M63, 2011.

[8] T. C. dos Santos, N. Rescignano, L. Boff et al., "Manufacture and characterization of chitosan/PLGA nanoparticles nanocomposite buccal films," Carbohydrate Polymers, vol. 173, pp. 638-644, 2017.

[9] S. Harms, K. Rätzke, F. Faupel, G. J. Schneider, L. Willner, and D. Richter, "Free volume of interphases in model nanocomposites studied by positron annihilation lifetime spectroscopy," Macromolecules, vol. 43, no. 24, pp. 10505-10511, 2010.

[10] S. Rivero, L. Damonte, M. A. García, and A. Pinotti, "An insight into the role of glycerol in chitosan films," Food Biophysics, vol. 11, no. 2, pp. 117-127, 2016.

[11] J. Lamarra, S. Rivero, and A. Pinotti, "Design of chitosanbased nanoparticles functionalized with gallic acid," Materials Science and Engineering: C, vol. 67, pp. 717-726, 2016.

[12] P. Calvo, C. Remunan-Lopez, J. L. Vila-Jato, and M. J. Alonso, "Novel hydrophilic chitosan-polyethylene oxide nanoparticles as protein carriers," Journal of Applied Polymer Science, vol. 63, no. 1, pp. 125-132, 1997.

[13] H. Muramatsu, K. Matsumoto, S. Minekawa, Y. Yagi, and S. Sasai, "Ortho-positronium annihilation parameters in polyvinyl alcohol films with various degrees of polymerization, saponification and crystallinity," Radiochimica Acta, vol. 89, no. 2, pp. 119-123, 2001.

[14] H. G. Peng, R. S. Vallery, M. Liu, M. Skalsey, and D. W. Gidley, "Depth-profiled positronium annihilation lifetime spectroscopy on porous films," Colloids and Surfaces A: Physicochemical and Engineering Aspects, vol. 300, no. 1-2, pp. 154-161, 2007. 
[15] C. G. da Rosa, C. D. Borges, R. C. Zambiazi et al., "Microencapsulation of gallic acid in chitosan, $\beta$-cyclodextrin and xanthan," Industrial Crops and Products, vol. 46, pp. 138-146, 2013.

[16] K. Nagpal, S. K. Singh, and D. N. Mishra, "Nanoparticle mediated brain targeted delivery of gallic acid: in vivo behavioral and biochemical studies for improved antioxidant and antidepressant-like activity," Drug Delivery, vol. 19, no. 8, pp. 378-391, 2012.

[17] G. V. Shavi, U.Y Nayak, M. S Reddy et al., "Sustained release optimized formulation of anastrozole-loaded chitosan microspheres: in vitro and in vivo evaluation," Journal of Materials Science: Materials in Medicine, vol. 22, no. 4, pp. 865-878, 2011.

[18] A. D. C. S. Alves, R. M. Mainardes, and N. M. Khalil, "Nanoencapsulation of gallic acid and evaluation of its cytotoxicity and antioxidant activity," Materials Science and Engineering: C, vol. 60, pp. 126-134, 2016.

[19] S. K. Sharma, K. Sudarshan, M. Sahu, and P. K. Pujari, "Investigation of free volume characteristics of the interfacial layer in poly (methyl methacrylate)-alumina nanocomposite and its role in thermal behavior," RSC Advances, vol. 6, no. 72, pp. 67997-68004, 2016.

[20] N. Mati-Baouche, H. De Baynast, C. Vial et al., "Physicochemical, thermal, and mechanical approaches for the characterization of solubilized and solid state chitosans," Journal of Applied Polymer Science, vol. 132, no. 2, pp. 41257-41265, 2015.

[21] C. Qiao, X. Ma, J. Zhang, and J. Yao, "Molecular interactions in gelatin/chitosan composite films," Food Chemistry, vol. 235, pp. 45-50, 2017.

[22] M. Ghozali and A. Haryono, "Effect of size of cellulose particle as filler in the PVC biocomposites on their thermal and mechanical properties," Materials Science Forum, vol. 737, pp. 67-73, 2013.

[23] A. Sujima-Anbu, S. V. Sahi, and P. Venkatachalam, "Synthesis of bioactive chemicals crosslinked sodium tripolyphosphate (TPP)-chitosan nanoparticles for enhanced cytotoxic activity against human ovarian cancer cell line (PA-1)," Journal of Nanomedicine \& Nanotechnology, vol. 7, no. 6, pp. 1-9, 2016.

[24] F. T. L. Muniz, M. A. Miranda, C. Morilla dos Santos, and J. M. Sasaki, "The Scherrer equation and the dynamical theory of X-ray diffraction," Acta Crystallographica Section A: Foundations and Advances, vol. 72, no. 3, pp. 385-390, 2016.

[25] K. Kanimozhi, S. K. Basha, and V. S. Kumari, "Processing and characterization of chitosan/PVA and methylcellulose porous scaffolds for tissue engineering," Materials Science and Engineering: C, vol. 61, pp. 484-491, 2016.

[26] T.-T. Hsieh, C. Tiu, and G. P. Simon, "Correlation between molecular structure, free volume, and physical properties of a wide range of main chain thermotropic liquid crystalline polymers," Journal of Applied Polymer Science, vol. 82, no. 9, pp. 2252-2267, 2001.

[27] V. T. Mardila, I. O. Wilandari, R. A. Shobirin, D. J. D. H. Santjojo, and A. Sabdurin, "In situ synthesis and characterization of chitosan- $\mathrm{Fe}_{3} \mathrm{O}_{4}$ nanoparticles using tripolyphosphate/citrate as crosslinker," Chemistry \& Chemical Engineering, Biotechnology, Food Industry, vol. 17, pp. 249-260, 2016.

[28] S. Biswas, S. Kar, S. Chaudhuri, and P. M. Nambissan, "Positron annihilation studies of defects and interfaces in $\mathrm{ZnS}$ nanostructures of different crystalline and morphological features," The Journal of Chemical Physics, vol. 125, no. 16, pp. 164-719, 2006.
[29] M. A. Moharram, K. M. T. Ereiba, W. El hotaby, and A. M. Bakr, "Synthesis and characterization of graphene oxide/crosslinked chitosan nanocomposite for lead removal form aqueous solution," Research Journal of Pharmaceutical, Biological and Chemical Sciences, vol. 4, pp. 1473-1489, 2015.

[30] M. Gierszewska-Druzyńska and J. Ostrowska-Czubenko, "The effect of ionic crosslinking on thermal properties of hydrogel chitosan membranes," Progress on Chemistry and Application of Chitin and its Derivatives, Polish Chitin Society, vol. 15, pp. 25-32, 2010.

[31] B. Hu, C. Pan, Y. Sun et al., "Optimization of fabrication parameters to produce chitosan-tripolyphosphate nanoparticles for delivery of tea catechins," Journal of Agricultural and Food Chemistry, vol. 56, no. 16, pp. 7451-7458, 2008.

[32] A. L. de Pinho Neves, C. C. Milioli, L. Müller, H. G. Riella, N. C. Kuhnen, and H. K. Stulzer, "Factorial design as tool in chitosan nanoparticles development by ionic gelation technique," Colloids and Surfaces A: Physicochemical and Engineering Aspects, vol. 445, pp. 34-39, 2014.

[33] O. Ramon, E. Kesselman, R. Berkovici, Y. Cohen, and Y. Paz, "Attenuated total reflectance/fourier transform infrared studies on the phase separation process of aqueous solutions of poly (n-isopropylacrylamide)," Journal of Polymer Science Part B: Polymer Physics, vol. 39, no. 14, pp. 1665-1677, 2001.

[34] S. Rivero, J. Lecot, and A. Pinotti, "Impregnation of kraft paper support with polylactic acid multilayers," Advanced Materials Letters, vol. 8, no. 6, pp. 741-751, 2017. 


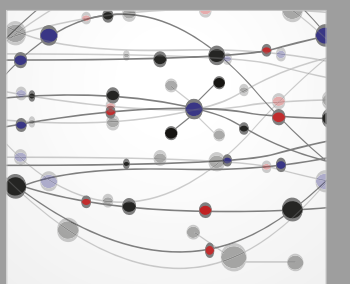

The Scientific World Journal
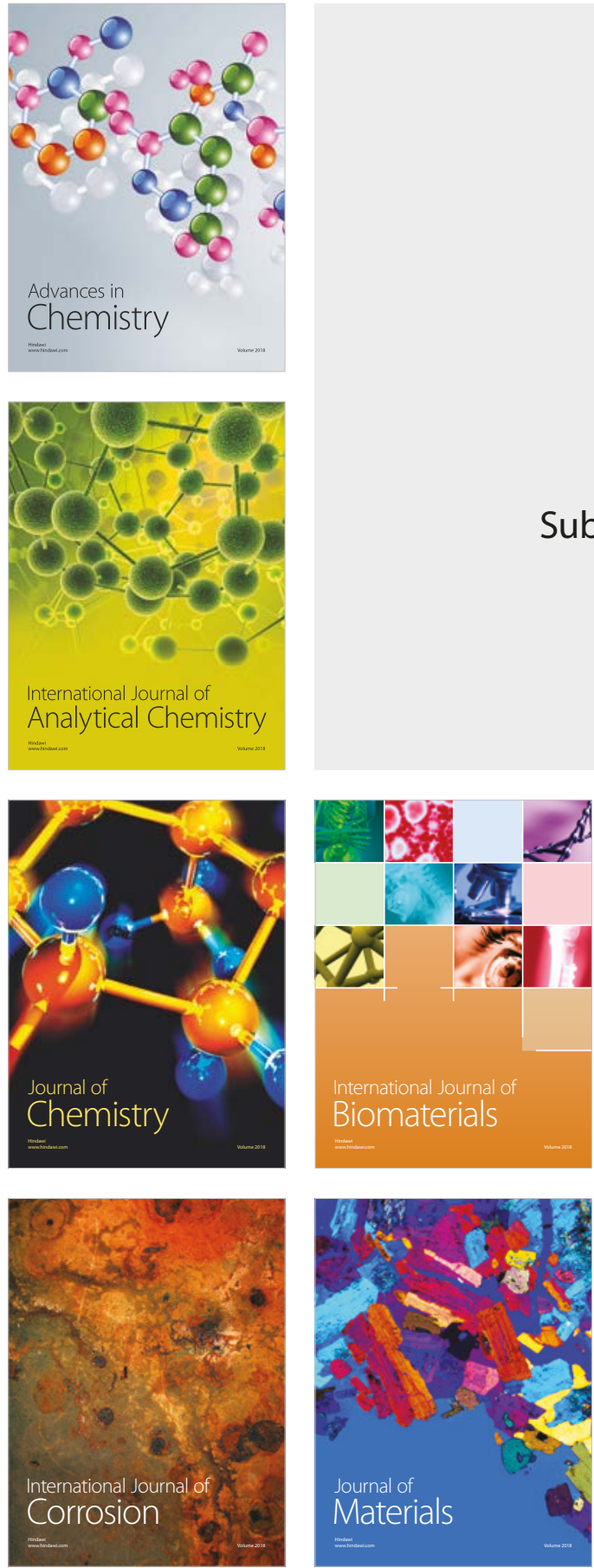

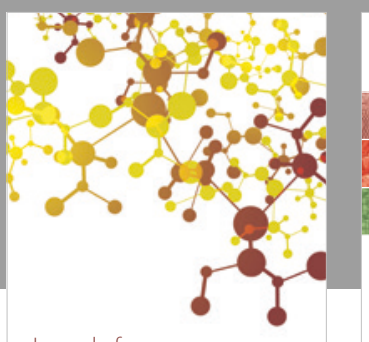

Journal of

Applied Chemistry
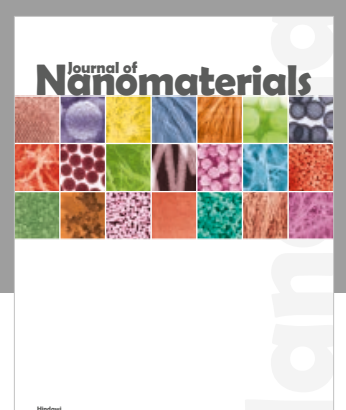

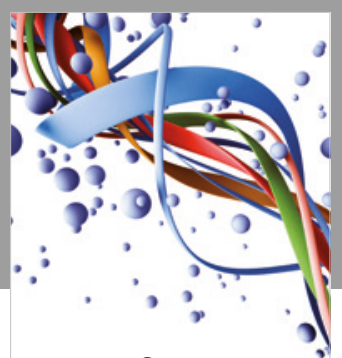

Scientifica

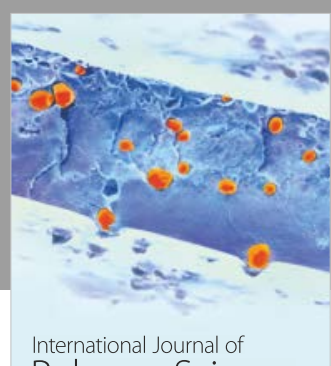

Polymer Science

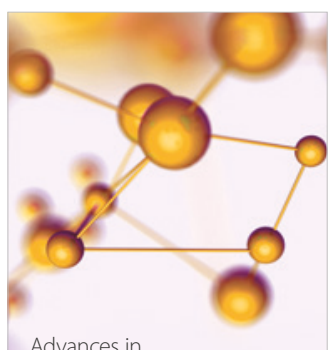

Physical Chemistry
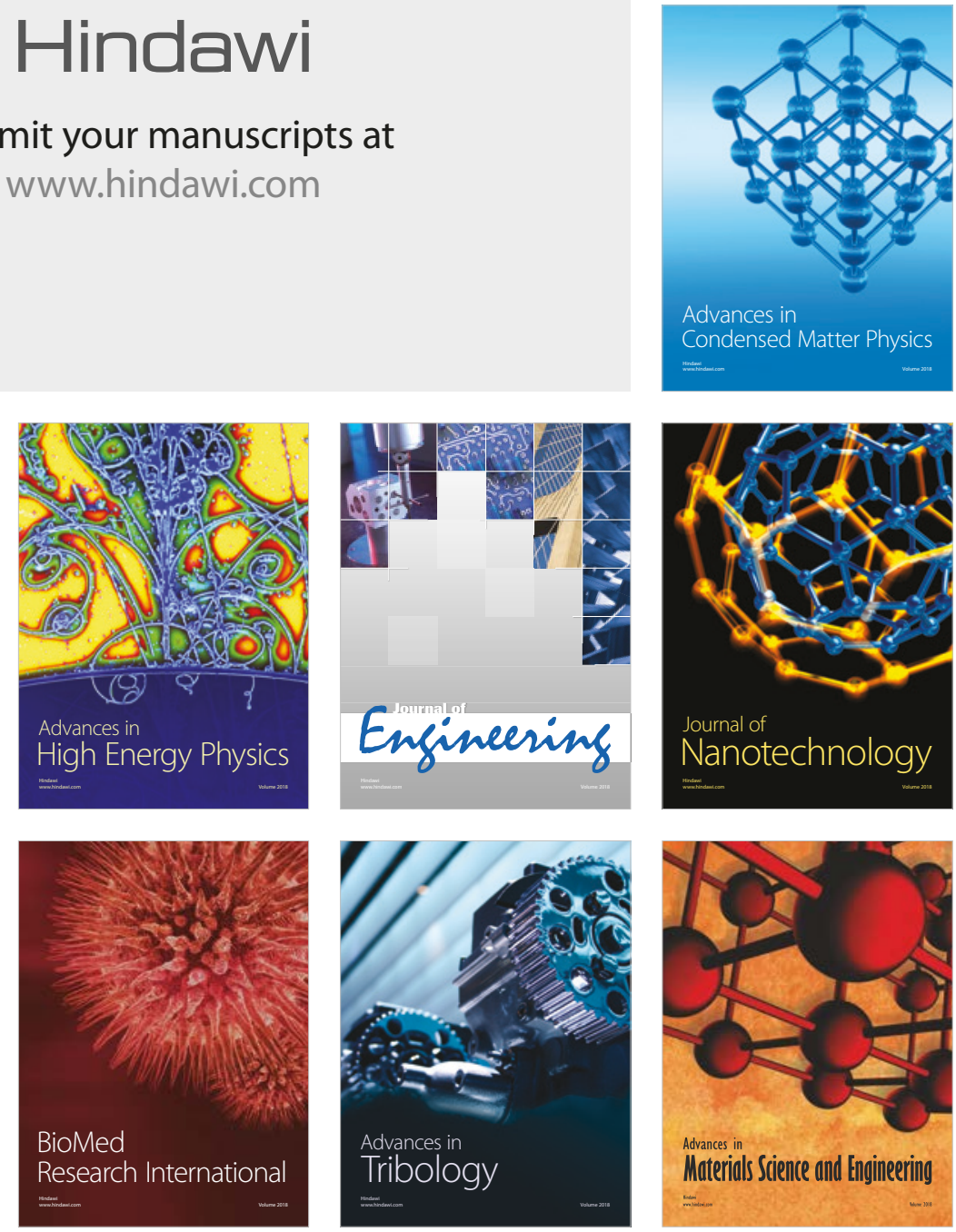